\title{
Cardiovascular Disease Risk Factors
}

\author{
Reza Amani and Nasrin Sharifi \\ Ahvaz Jondishapour University of Medical Sciences,
}

Iran

\section{Introduction}

Cardiovascular disease (CVD) is the leading cause of death not only in industrialized and developed countries but also in developing societies (WHO, 2008a). Changes in lifestyle of the population living in developing countries, which is due to the socioeconomic and cultural transition, are important reasons for increasing the rate of CVD. This observation has led to extensive research on prevention. Diagnosis the risk factors and predictors of CVD can help us detect high risk patients and prevent the disease, effectively.

Nowadays with a rapid progress in medical technology and diagnostic tools, more predictors are being added to the previous list of CVD risk factors. Therefore, we need to design updated risk assessment methods to screen high risk individuals early in their life span.

This chapter defines cardiovascular risk factors, classifies them, briefly describes how they interact, and discusses what strategies Should be implemented to prevent CVD progression.

\section{Definitions}

\subsection{Coronary Heart Disease (CHD)}

Coronary heart disease (CHD) is a condition in which the walls of arteries supplying blood to the heart muscle (coronary arteries) become thickened. This thickening, caused by development of lesions in the arterial wall, is called atherosclerosis; the lesions are called plaques. It can restrict the supply of blood to the heart muscle (the myocardium) and may manifest to the patient as chest pain on exertion (angina) or breathlessness on exertion. (Frayn 2005).

\subsection{Cerebrovascular disease}

Cerebrovascular disease involves interruption of the blood supply to part of the brain and may result in a stroke or a transient ischemic attack. The loss of blood supply to part of the brain may lead to irreversible damage to brain tissue. The blockage most commonly arises from the process of thromboembolism, in which a blood clot formed somewhere else (e.g. in the heart or in the carotid artery) becomes dislodged and then occludes an artery within the brain (cerebral arteries). Narrowing of the intracerebral arteries with atherosclerotic plaque may increase the risk, and may also lead to local formation of a blood clot. The etiology is similar to that of CHD (Frayn 2005). 


\subsection{Peripheral Vascular Disease (PVD)}

Peripheral vascular disease (PVD) involves atherosclerotic plaques narrowing the arteries supplying other regions apart from the myocardium and brain. A common form involves narrowing of the arteries supplying blood to the legs. The result may be pain on exercise. In more severe cases, impaired blood supply leads to death of leg tissues, which requires amputation (Frayn 2005).

\section{Epidemiology}

\subsection{Global and regional trends in CVD burden}

In recent years, the dominance of chronic diseases as major contributors to total global mortality has emerged (WHO, 2008a). By 2005, the total number of cardiovascular disease (CVD) deaths (mainly coronary heart disease, stroke, and rheumatic heart disease) had increased globally to 17.5 million from 14.4 million in 1990(WHO, 2009a).

The World Health Organization (WHO) estimates there will be about 20 million CVD deaths in 2015, accounting for 30 percent of all deaths worldwide (WHO, 2005). Thus, CVD is today the largest single contributor to global mortality and will continue to dominate mortality trends in the future (WHO, 2009a).

Globally, there is an uneven distribution of age-adjusted CVD mortality that is mapped in Figure 1. The lowest age-adjusted mortality rates are in the advanced industrialized countries and parts of Latin America, whereas the highest rates today are found in Eastern Europe and number of low and middle income countries(WHO, 2008a). The broad causes for the rise and, in some countries, the decline in CVD over time are well described. The key contributors to the rise across countries at all stages of development include tobacco use and abnormal blood lipid levels, along with unhealthy dietary changes (especially related to fats and oils, salt, and increased calories) and reduced physical activity(Hu, 2008; ). Key contributors to the decline in some countries include declines in tobacco use and exposure, healthful dietary shifts, population-wide prevention efforts, and treatment interventions (Shafey et al, 2009; Davies et al, 2007).

\section{Pathophysiology}

Cardiovascular diseases, whether affecting the coronary, cerebral or peripheral arteries, share a common pathophysiology involving atherosclerosis and thrombosis (or clotting).

\subsection{Atherosclerosis}

Atherosclerosis is the most common cause of CVD and related mortality. The first observable event in the process of atherosclerosis is the accumulation of plaque (cholesterol from low-density lipoproteins [LDLs], calcium, and fibrin) in large and medium arteries.

This plaque can grow and produce ischemia either by insufficient blood flow if there is a high oxygen demand or by rupturing, forming a thrombus and occluding the lumen (Rudd et al., 2005). Only high-risk or vulnerable plaque forms thrombi. Characteristics of vulnerable 


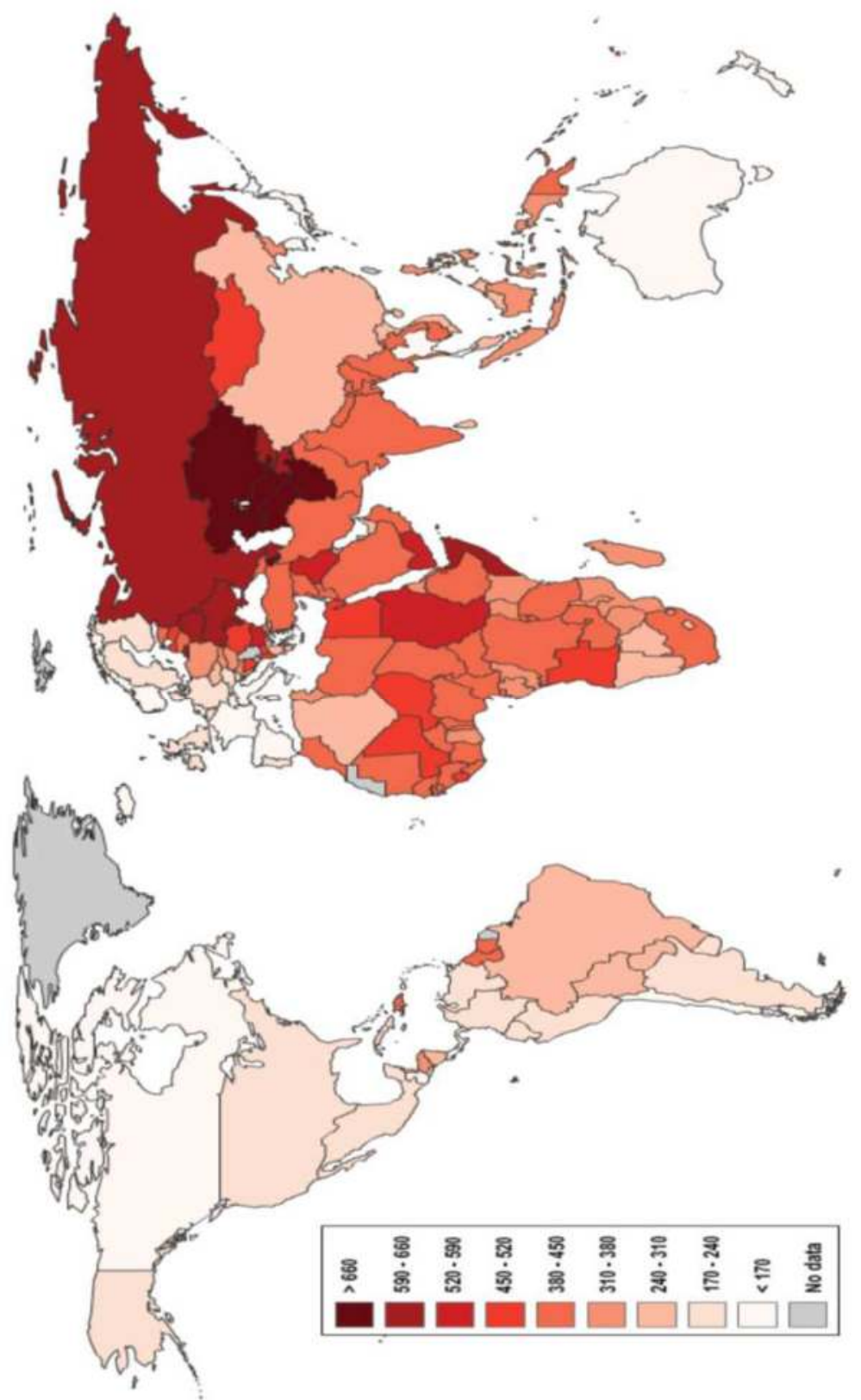

NOTE: Rates are age-standardized to WHO's world standard population. SOURCES: WHO, 2009a

Fig. 1. Age-standardized deaths due to cardiovascular disease (rate per 100,000), 2004. 
plaque are lesions with a thin fibrous cap, few smooth muscle cells, many macrophages (inflammatory cells),and a large lipid core( Figure 2 ) (Rudd et al., 2005). The site of plaque formation or atherogenesis is the endothelium in the artery wall. Normally the endothelium promotes dilation of the blood vessel ,less smooth muscle cell growth, and prevention of an anti-inflammatory response (Davignon and Ganz, 2004). In atherosclerosis the endothelium becomes dysfunctional before an atheroma or plaque, a more serious lesion, develops. This endothelial dysfunction results in the production of less nitric oxide, a key vasodilator, and the blood vessel becomes more constricted .It also becomes more permeable and allows LDL cholesterol to be taken up by macrophages, which then accumulate and form foam cells and eventually an early lesion known as a fatty streak.

\section{Risk factors for cardiovascular disease}

This section described the major risk factors for CVD in more detail. The section begins with lipid and inflammation-related factors, behavioral risk factors, including tobacco use, dietary factors, alcohol, and physical activity. This is followed by the major biological risk factors that mediate the role of these behaviors leading to CVD, including obesity, blood pressure, blood lipids, and diabetes.

\subsection{Modifiable cardiovascular risk factors}

\subsubsection{Lipid-related factors}

Lipid-related cardiovascular risk factors have attracted enormous attention over the past years, and consensus documents have been produced to implement treatment and preventive strategies. Essentially, this applies to the conventional risk factors such as high plasma total and low-density lipoprotein (LDL) cholesterol, low plasma high density lipoprotein (HDL) cholesterol and elevated plasma triglycerides.

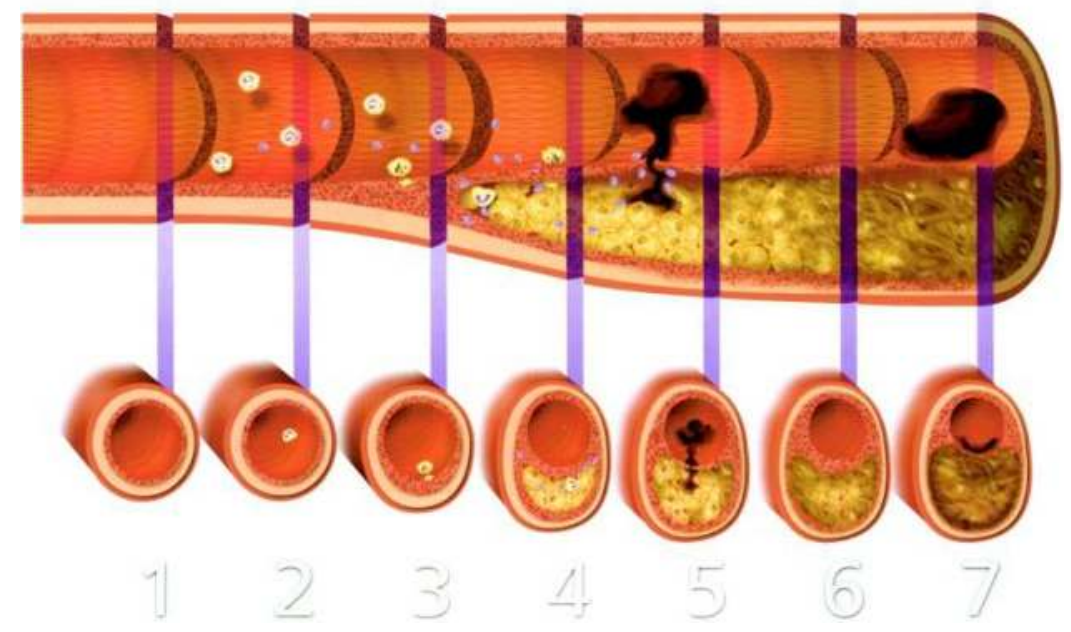

Fig. 2. Natural Progression of atherosclerosis 


\subsubsection{Atherogenic lipoproteins}

A number of factors determine whether a cholesterol-containing lipoprotein particle resident in plasma has atherogenic properties. The size of the particle determines the ease by which the endothelium can be penetrated; small particles are more likely to be deposited in the arterial wall than large particles. The binding to the subendothelial matrix is also dependent on size, in which the smaller particles bind more avidly to proteoglycans (Anber et al., 1997). The apoB protein, present as one molecule per lipoprotein particle, seems to be crucial. Firstly, lipoprotein particles without apoB are not atherogenic; secondly, apoB has multiple proteoglycan binding domains which enhance the retention of the particle in the subendothelial matrix (Skalen et al., 2002). Finally, physicochemical and compositional characteristics, such as resistance factors against oxidative stress, are likely to be important in reducing the modification of lipoprotein particles.

\subsubsection{Small, dense Low-Density Lipoprotein (LDL)}

The formation of small, dense LDL particles is complex and can be seen as a genetic trait, but the major gene(s) responsible remain unknown. Environmental factors also play a major role, in that dietary factors can influence triglyceride as a major determinant. In vitro studies have shown that small, dense LDL particles are formed by sequential exchange of lipids between LDL and triglyceride-rich lipoproteins. The cholesteryl esters contained in the core of the LDL particle are exchanged for triglycerides by the cholesteryl ester transfer protein (CETP). Triglycerides entering the LDL particle are hydrolyzed by hepatic lipase and the core volume of the particle is reduced. The formation of small, dense LDL is limited by the availability of triglyceride-rich lipoproteins, as evidenced by the close positive correlation between plasma triglycerides and small, dense LDL. It is assumed that these processes take quite some time and the end product is therefore an aged particle that has lost its defense against free radical attack. The retention in plasma of the particle is partly due to the fact that small, dense LDL has a lower affinity for the LDL receptor than normal buoyant LDL (Nigon et al., 1991). It is thought that a consequence of the altered chemical composition of the small, dense LDL particle is that it more avidly binds to the subendothelial matrix and upon challenge more easily undergoes oxidative modification thereby triggering foam cell formation (Tribble et al., 1992; Chait et al., 1993; Dejager et al., 1993;).

The presence of triglyceride-rich lipoproteins is a principal modulator of small, dense LDL; the plasma concentration of the latter is strongly and positively related to the concentration of plasma triglycerides. In fact, all examples in which the triglyceride concentration has been altered to observe a change in the LDL profile are consistent: elevation of triglycerides leads to higher abundance of small, dense LDL; the opposite is observed when triglycerides are lowered, treated by diet or pharmacological agents. Low fat diets may lead to increased plasma triglyceride concentration; consequently a reduction in LDL size was observed in a study of 105 men switching from a high fat $(46 \%)$ to a low fat $(24 \%)$ diet (Dreon et al., 1994). The total LDL cholesterol concentration was, however, reduced simultaneously, so the net effect on cardiovascular risk is not entirely clear.

In the Quebec Cardiovascular Study the cholesterol concentration in small dense LDL particle may give even more precise information. Again, in the Quebec heart study, the cholesterol concentration in small dense LDL particles showed the strongest association with the risk of CHD. These data suggest that the cholesterol within small dense LDL is 
particularly harmful. Therefore measurement of LDL particle size and possibly cholesterol content within these particles may enhance our capability to predict cardiovasular events (Lamarche et al., 2001).

\subsubsection{High-Density Lipoprotein (HDL)}

HDL is another lipid profile fraction which is associated to the risk of CVD. Decreased levels of HDL-c correlated to increased risk of CVD. The atheroprotective role for HDL is mainly due to the pathway named reverse cholesterol transport (RCT). RCT is defined as the uptake of cholesterol from peripheral tissues back to the liver by HDL. Apo A1 is an apolipoprotein of the HDL that activates the enzyme lecithin-cholesteryl ester acyl-transferase (LCAT). The main function of LCAT is transferring cholesterol from cell to HDL. Both apo C and apo E on HDL are transferred to chylomicrons.

Apo E helps receptors metabolize chylomicron remnants and also inhibits appetite (Gotoh et al., 2006). Therefore high HDL levels are associated with low levels of chylomicrons; very low density lipoprotein (VLDL) remnants; and small dense LDLs and subsequently lower atherosclerotic risk. HDL has other potentially atheroprotective properties. The antioxidative activity of HDL is typically characterized by its ability to inhibit LDL oxidation. It has also been shown to inhibit the formation of reactive oxygen species. HDL can help to protect endothelial cells from apoptosis induced by mildly oxidized LDL. It can affect platelet function through the promotion of nitric oxide production (Chen et al, 1994; Suc et al 1997) and coagulation by the inhibition of several coagulation factors. There is considerable evidence for a direct protective role of HDL in inflammatory, oxidative, apoptotic, and thrombotic processes.

Major factors that increase HDL cholesterol level are exogenous estrogen, intensive exercise, loss of excess body fat, moderate consumption of alcohol and triglyceride lowering drugs such as fibrates and niacin. Treatment of low serum levels of HDL-C in at risk patients is an important therapeutic intervention and impacts rates of disease progression as well as cardiovascular events (Scanu and Edelstein , 2008).

\subsubsection{Inflammation-related factors}

Inflammation is a part of atherosclerosis process, beginning with the formation of fatty streak underlying the endothelium of large arteries. The infiltration of monocytes and lymphocytes occurs as a result of the expression of adhesion molecules by endothelial cells lining the artery wall. Several stimuli for the inflammatory response in atherosclerosis have been proposed in which oxidised low-density lipoprotein (LDL), is of most importance. Monocytes that have infiltrated the arterial intima and differentiated into macrophages take up oxidized LDL through scavenger receptors in an unregulated manner, accumulating large amounts of cholesterol and becoming foam cells. Macrophages eventually die, through necrosis and apoptosis, the lipid is deposited within the core of the developing plaque (Figure 3). Cytokines secreted by both lymphocytes and macrophages within the plaque exert pro- and anti-atherogenic effects on components of the vessel wall. Smooth muscle cells migrate from the medial portion of the arterial wall towards the intima and secrete extracellular matrix proteins that form a fibrous cap. The cap separates the highly thrombogenic contents of the plaque lipid core from the potent coagulation system contained within the circulating blood. 
This chronic, low-grade inflammation is likely to be the result of cytokines secreted by monocytes and soluble adhesion molecules from the vessel wall into the circulation, where they subsequently act on the liver to induce the secretion of acute phase proteins, including C-Reactive Protein(CRP), fibrinogen and serum amyloid A (Frayn, 2005).

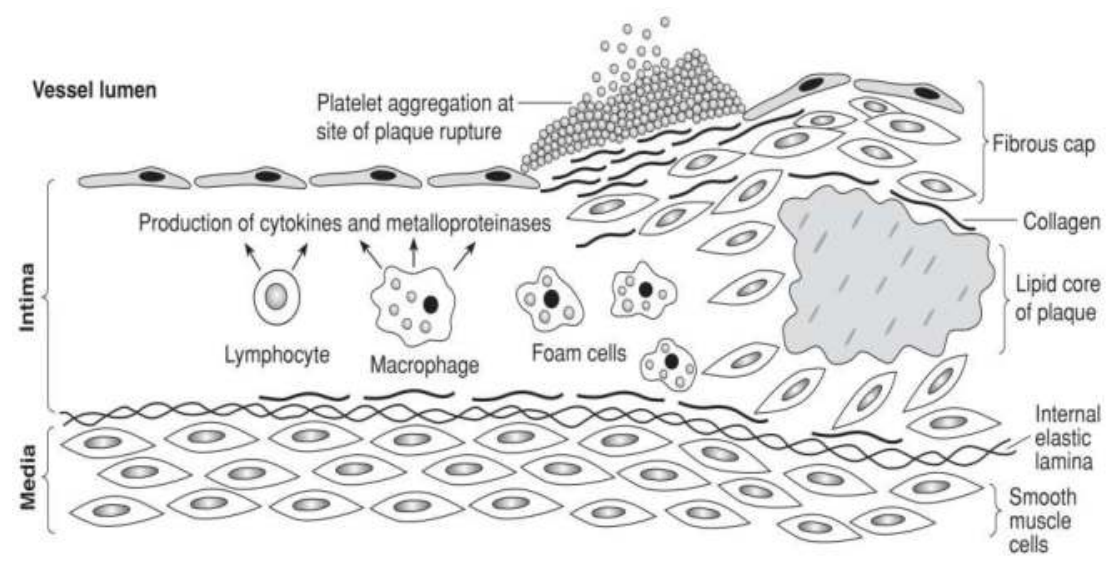

From Frayn 2005

Fig. 3. Schematic representation of the development of an atherosclerotic lesion, showing plaque rupture and platelet aggregation .

\subsubsection{C-Reactive protein}

Multiple studies have demonstrated that elevated levels of high-sensitivity C-reactive protein (hs-CRP) are associated with increased CVD risk (Buckley et al.,2009; Musunuru et al., 2008). hs-CRP, previously considered to be an indicator of systemic inflammation, has recently received much attention in the scientific literature, not only as a potential marker of increased atherosclerotic risk, but also as a potential target of therapy for the prevention of atherosclerotic CVD. Evidence derived mainly from statin trials, supports the potential value of CRP as a therapeutic target for both primary and secondary prevention of CVD and $\mathrm{CHD}$. The largest study to suggest an integral role for CRP as a target for therapy in primary prevention of CVD is the recent Justification for the Use of Statins in Prevention: An Intervention Trial Evaluating Rosuvastatin (JUPITER) trial. The investigators randomized 17,802 men $\geq 50$ years of age and women $\geq 60$ years of age with low LDL cholesterol levels < $130 \mathrm{mg} / \mathrm{dL}$ and hs-CRP $\geq 2 \mathrm{mg} / \mathrm{L}$ and no history of CVD or diabetes to $20 \mathrm{mg}$ rosuvastatin daily or placebo. The primary end point was the first occurrence of MI, stroke, hospitalization for unstable angina, arterial revascularization, or CV death (Ridker et al; 2008). During the 1.9-year median follow-up duration (maximum follow-up period 5 years), rosuvastatin reduced LDL cholesterol by $50 \%$ and hs-CRP by $37 \%$. Thus, JUPITER demonstrated a magnitude of effect larger than that of almost all prior statin trials (Ridker et al; 2009). Based on the results of the JUPITER study, the U.S. Food and Drug Administration (FDA) in February 2010 agreed to broader labeling for rosuvastatin. Rosuvastatin is currently approved for the reduction of risk for stroke, MI, and revascularization procedures in individuals who have normal LDL cholesterol levels and no clinically evident CHD but who do have an increased risk based on age, CRP levels, and the 
presence of at least one additional CVD risk factor. Accordingly, JUPITER not only demonstrated that hs-CRP successfully identified a population with "hidden risk" for CVD but also provided additional evidence for the potential utility of hs-CRP as a target for therapy in primary prevention of CVD disease.

Other inflammatory states such as obesity produce elevations in CRP even in young obese children (Blum et al., 2005). Body mass index (BMI) is moderately correlated ( $r=0.5)$ to CRP levels (Rawson et al., 2003). Recently it was demonstrated that weight loss lowers CRP (Tchernof et al., 2002), which provides another physiologic benefit for weight management as a preventive strategy for CHD reduction. Currently it is known that elevated insulin levels in overweight children affect CRP. Physical activity did not appear to be related (Rawson et al., 2003). To date few studies have investigated the effects of dietary variables on CRP. In a cross-sectional study, higher intakes of fruits and vegetables were associated with lower CRP levels (Gao et al., 2004).

\subsubsection{Fibrinogen}

Fibrinogen is the precursor of fibrin. As the major clotting factor in the blood and a proinflammatory molecule, fibrinogen plays role in atherosclerosis. It is synthesized in the liver and, like CRP, is an acute phase protein, whose circulating levels can change during acute responses to tissue damage or infection. Thus Fibrinogen (Fg) is a biomarker of inflammation (Ross 1999), which, when elevated, indicates the presence of inflammation and identifies individuals with a high risk for cardiovascular disorders. Increased plasma Fg concentration typically accompanies hypertension development (Lominadze et al. 1998) and stroke (D'Erasmo et al. 1993). Factors associated with an elevated fibrinogen are smoking, diabetes, hypertension, obesity, sedentary lifestyle, elevated triglycerides, and genetic factors. Recent studies indicate that increased Fg content affects microcirculation by increasing plasma viscosity, RBC aggregation and platelet thrombogenesis (Lominadze et al; 2010). These changes lead to vascular dysfunction and exacerbate microcirculatory complications during cardiovascular diseases (figure 4).

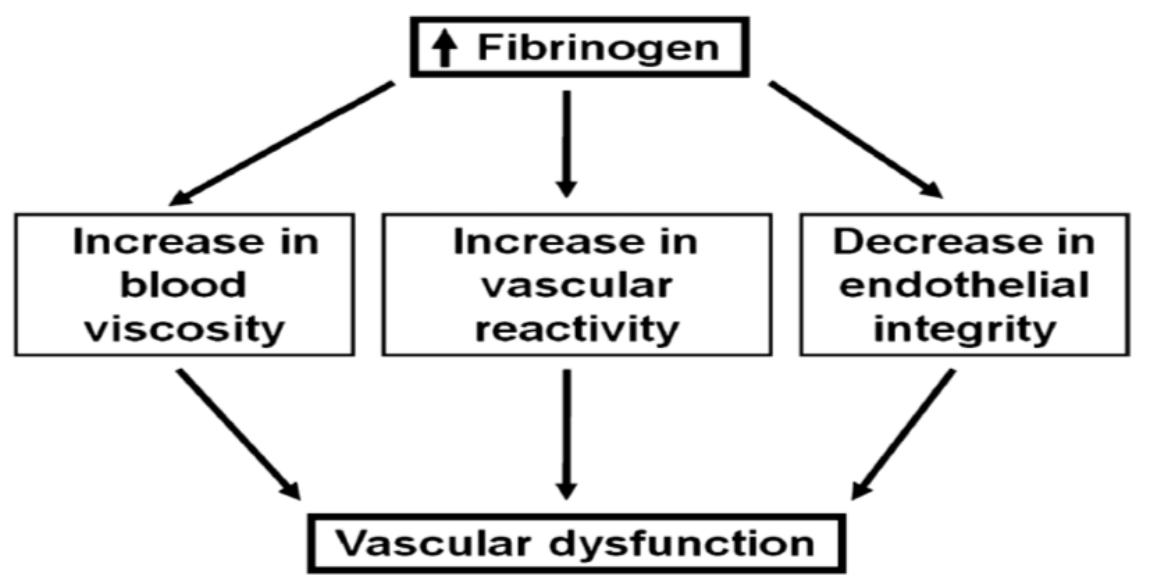

From Lominadze et al. 2010

Fig. 4. Schematic representation of fibrinogen-induced vascular dysfunction. 


\subsubsection{Serum amyloid $A$}

Serum amyloid A (SAA) is a precursor of amyloid A protein and comprises both constitutive (apoSAA1, apoSAA2) and acute phase (apoSAA4) isoforms. The serum amyloid A proteins are a family of inflammatory apolipoproteins with a high affinity for HDL, and their production by the liver and other tissues is thought to be induced by IL- 1 and IL 6 . Their role in lipid metabolism is unclear, although they may be involved in HDL trafficking. A small number of studies have investigated the association between SAA and the incidence of CHD ( Ridker et al., 1998, 2000; Danesh et al., 2000b). Taken together, these studies show that a comparison of individuals with values in the top third with those in the bottom third gives a combined risk ratio of 1.6 for CHD. However, further studies are required to determine whether the association is independent of possible confounders.

\subsubsection{Behavioral and lifestyle risk factors}

\subsubsection{Tobacco}

There are currently more than 1 billion smokers worldwide. Although use of tobacco products is decreasing in high income countries, it is increasing globally, with more than 80 percent of the world's smokers now living in low and middle income countries (Jha and Chaloupka, 1999).

In the Global Burden of Disease study, Lopez et al. (2006) estimated that in 2000, 880,000 deaths from CHD and 412,000 deaths from stroke were attributable to tobacco. Smoking cessation has been shown to have significant impacts on reducing CHD. In a major review of the evidence, Critchley and Capewell (2003) determined that successful smoking cessation reduced CHD mortality risk by up to 36 percent. Smoking cessation leads to significantly lower rates of reinfarction within 1 year among patients who have had a heart attack and reduces the risk of sudden cardiac death among patients with CHD (Gritz et al., 2007).

Two major trends are of real concern with respect to the future of tobacco-related CVD. First, in most parts of the world, the smoking rates are higher among the poorest populations (WHO, 2008b). The second worrisome trend is in smoking among girls (IOM, 2010).

In addition to active smoking, it has become increasingly apparent that exposure to secondhand smoke significantly increases cardiovascular risk. A recent IOM review of the effects of secondhand smoke exposure concluded that exposure to secondhand smoke significantly increases cardiovascular risk and that public smoking bans can significantly reduce the rate of heart attacks. The report concluded that secondhand smoke exposure increases cardiovascular risk by 25 to 30 percent and that there is sufficient evidence to support a causal relationship between secondhand smoke exposure and acute myocardial infarction (AMIs). This causality was reinforced by the report's conclusion that smoking bans significantly reduce the rate of AMIs, with declines ranging from 6 to 47 percent (IOM, 2009).

\subsubsection{Dietary factors}

The relationship between CVD and diet is one of the most studied relationships in epidemiology. Although nutritional research has traditionally focused on the effect of 
individual food groups or nutrients on CVD, there has been a shift in recent years toward comparing how different types of dietary patterns in their entirety affect CVD risk (IOM, 2010). The following sections reflect this shift by discussing research on dietary factors that have clear impacts on CVD risk.

\subsection{Dietary fat}

Healthy oils are those that contain no commercially introduced trans fatty acids, are low in saturated fatty acids, and are high in mono- and polyunsaturated fatty acids.

There is accumulating evidence that it is fat quality (the type of dietary fat), rather than the total amount of fat, that is particularly important for cardiovascular disease (Astrup, 2002).

\subsection{Saturated Fatty Acids (SFA)}

The predominant sources of SFAs are animal foods (meat and dairy). SFAs have the most potent effect on LDL cholesterol, which rises in a dose response fashion when increasing levels of SFAs are consumed. In our study, consumption of habitual hydrogenated fats and full-fat yoghurts (fat content more than 2.5\%) increased the risk of CVD (OR $=2.12(1.23-$ 3.64) and 2.35(1.32-4.18), respectively) (Amani et al, 2010). These foods are the major sources of SFAs. SFAs intake is the principal determinant of total cholesterol(TC) and CVD and substitution of $1 \%$ carbohydrate calories by SFAs increases TC by $1.5 \mathrm{mg} / \mathrm{dL}$ (Joseph et al, 2000). Of all the added fats in the diet, the most hypercholesterolemic promoting are palm kernel, coconut, and palm oils; lard; and butter. SFAs raise serum LDL cholesterol by decreasing LDL receptor synthesis and activity. Regardless of form, all fatty acids lower fasting triglycerides if they replace carbohydrate in the diet. In secondary prevention trials replacement of SFAs with MUFA, a-linolenic acid, and increased fruits and vegetables prevented fatal and nonfatal CVD events in persons with established disease (de Lorgeril, 1999). Thus fatty acids affect disease progression through lipids and other mechanisms and possibly through inflammation and thrombosis (Krummel, 2008).

\subsection{Monounsaturated Fatty Acids (MUFA)}

The American Heart Association (AHA) does not have any recommendation for the cis form of MUFAs (Lichtenstein et al., 2006). Oleic acid (C18:1) is the most prevalent MUFA in the American diet. Substituting oleic acid for carbohydrate has almost no appreciable effect on blood lipids; however, replacing SFAs with MUFA lowers serum cholesterol levels, LDL cholesterol levels, and triglyceride levels to about the same extent as polyunsaturated fatty acids (PUFAs ). The effects of MUFAs on HDL cholesterol depend on the total fat content of the diet. When intakes of both MUFA ( $>15 \%$ of total kilocalories) and total fat $(>35 \%$ of kilocalories) are high, HDL cholesterol does not change or increases slightly compared with levels with a lower-fat diet (Krummel , 2008). Oleic acid as a part of the Mediterranean diet has been shown to have antiinflammatory effects. In epidemiologic studies high-fat diets of people in Mediterranean countries have been associated with low blood cholesterol levels and CHD incidence (Trichopoulou et al., 2003). Among other factors, the main fat source is olive oil, which is high in MUFA. Although higher-fat diets (low in SFA with MUFAs as the predominant fat) can lower blood cholesterol, they should be used with caution because of the caloric density of high-fat diets and the results of clinical trials, which have shown new atherosclerotic lesions in men who consume higher-fat diets. The negative association between the Mediterranean diet and CHD could be the result of factors other than MUFA 
intake. For example, these populations consume more fruits and vegetables, bread, cereals, fish, and nuts, and less red meat than many populations. Olive oil is the primary source of fat, and eggs are consumed from zero to four times per week (krummel, 2008).

\subsection{Polyunsaturated Fatty Acids (PUFA)}

The essential fatty acid linoleic acid (LA) is the predominant PUFA consumed in the American diet (Krummel, 2008). Population studies have demonstrated a negative correlation between LA intake and CHD rates (Wijendran and Hayes, 2004). Similarly, a meta analysis of 60 controlled human trials found that replacing PUFA for carbohydrate in the diet resulted in a decline in serum LDL cholesterol (Mensink et al., 2003). When SFAs are replaced with PUFAs in a low-fat diet, LDL and HDL cholesterol levels will be lowered. The lipid lowering effects of LA depend on the total fatty acid profile of the diet (Wijendran and Hayes, 2004). When added to study diets, large amounts of LA diminished levels of HDL cholesterol serum levels (Karmally, 2005). Studies suggest that high intakes of n-6 PUFAs may exert adverse effects on the function of vascular endothelium or stimulate production of proinflammatory cytokines. A low ratio of omega-6:omega-3 PUFA is recommended (Basu et al., 2006; Gibauer eial., 2006).

\subsection{Omega-3 fatty acids}

Fish oils, fish oil capsules, and ocean fish are rich source of the two main omega-3 fatty acids (i.e., eicosapentaenoic acid (EPA) and docosahexaenoic acid [DHA]). Many studies have shown that eating fish is associated with a decreased CVD risk. The recommendation for the general population for fish consumption is to eat fish high in omega-3 fatty acids (salmon, tuna, mackerel, sardines) at least twice a week (Psota et al., 2006). For patients who have CVD, $1 \mathrm{~g}$ of EPA and DHA combined is recommended from fish if possible but, if not, then from supplements (Lichtenstein et al., 2006). Patients who have hypertriglyceridemia need 2 to $4 \mathrm{~g}$ of EPA and DHA per day for effective lowering (Lichtenstein et a1.,2006). Omega-3 fatty acids lower triglyceride levels by inhibiting VLDL and apo B-100 synthesis and by decreasing postprandial lipemia.

a-Linolenic acid (ALA), an omega-3 fatty acid from vegetables, has anti-inflammatory effects. CRP levels were reduced when male patients consumed $8 \mathrm{~g}$ of ALA daily; similar results have not been observed for fish oil supplementation (Basu et a1.,2006). Omega-3 fatty acids also interfere with blood clotting by altering prostaglandin synthesis (Krummel, 2008).

\subsection{Trans fatty acids}

Trans-fatty acids are produced in the hydrogenation process used in the food industry to increase shelf life of foods and to make margarines, firmer (Krummel ,2008). The AHA (Lichtenstein et al., 2006) recommends no more than 1\% of calories (about 1-3 g/day) from trans-fatty acids. These fatty acids raise LDL cholesterol; however, effects on inflammation have been conflicting (Basu et a1.,2006). Most trans-fatty acids intake comes from partially hydrogenated vegetable oils (krummel, 2008).

Mozaffarian et al (2007) showed that partially hydrogenated oils are extensively being used for cooking in Iranian homes with average per-person intake of $14 \mathrm{~g} / 1000 \mathrm{kcal}$. Trans fatty acids (TFAs) accounted for $33 \%$ of fatty acids in these products, or $4.2 \%$ of all calories consumed (12.3 g/day). Consumption of hydrogenated fats was associated with higher 
CAD risk (OR $=2.12(1.23-3.64))$ in a study performed by Amani et al (2010). On the basis of TC:HDL-cholesterol effects alone, $9 \%$ of CHD events would be prevented by replacement of TFA in homes with cis-unsaturated fats ( $8 \%$ by replacement with saturated fats). On the basis of relationships of TFA intake with CHD incidence in prospective studies, 39\% of CHD events would be prevented by replacement of TFA with cis-unsaturated fats $(31 \%$ by replacement with saturated fats).

\subsection{Dietary cholesterol}

Dietary cholesterol raises total cholesterol and LDL cholesterol but to a lesser extent than SFAs. The AHA dietary patterns contain no more than $200 \mathrm{mg}$ of cholesterol each day (Krummel; 2008). There is a threshold beyond which addition of cholesterol to the diet has minimal effects. When cholesterol intakes reach $500 \mathrm{mg} /$ day, only small increments in blood cholesterol occur. Cholesterol responsiveness also varies widely among individuals. Some people are hyporesponders (i.e., their plasma cholesterol level does not increase after dietary cholesterol challenge), whereas others are hyperresponders (i.e., their plasma cholesterol level responds more strongly than expected to a cholesterol challenge). It has been suggested that hyperresponders may have the apo E- 4 allele and poor rates of conversion of cholesterol to bile acids, which causes elevated LDL cholesterol. Feedings cholesterol to animals enriches lipoproteins, which are atherogenic beyond just the rise in serum cholesterol (Krummel, 2008).

SFAs and cholesterol synergistically affect LDL cholesterol level, decrease LDL receptor synthesis and activity, increase VLDLs enriched with apo E, increase all lipoproteins, and decrease chylomicron size ( which is associated with CHD risk). The effect of dietary cholesterol on inflammatory factors has been inconsistent (Basu et a1.,2006).

\subsection{Dietary sodium}

There is evident that excessive sodium intake significantly increases CVD risk and that reduction in sodium intake at the population level decreases CVD burden (He and MacGregor, 2009, IOM, 2010 ). The most well-established mechanism by which sodium intake increases CVD risk is increasing blood pressure (BP). Numerous studies have found that there is a continuous and graded relationship between salt intake and blood pressure. In their recent major review of sodium trends and impact, He and MacGregor concluded that a reduction in salt from the current global intake of 9 to $12 \mathrm{~g} /$ day to the recommended levels of 5-6 g/day would have a major impact on BP and CVD (He and MacGregor, 2009; IOM, 2010). Salt's impact on CVD, however, extends beyond blood pressure. Animal and epidemiological studies have found that a diet high in sodium may directly increase the risk of stroke, which is independent and additive to salt's effect on BP (He and MacGregor, 2009 ; IOM, 2010).

\subsection{Soy protein}

In recent years, a great deal of interest has emerged in the role of soy-bean isoflavones in reducing heart diseases, and isoflavones might be responsible, in part, for the ability of soybean to lower the risk of CVD and atherosclerosis (Anderson et al, 1995). Anderson suggested that about $60-70 \%$ of the cholesterol lowering effect of soy protein may be due to its isoflavone content (Anderson et al, 1995). Isoflavones are a group of phytoestrogens which occur mainly in soy and it is consumed for the purpose of both promoting health and preventing several chronic diseases, including coronary heart disease, cancers of 
reproductive organs and osteoporosis ( Lichtenstein, 1998 ; Anerson et al, 1999). Aglycone forms of soy isoflavones especially genistein and daidzein have greatly been studied because of their greater estrogenic and antioxidant activities (Arora et al, 1998). Soy isoflavones have been shown to decrease total, VLDL and LDL cholesterol levels while increasing HDL cholesterol levels in peripubertal rhesus monkeys fed soy protein-based diets (Antony et al, 1996). It is claimed that purified isoflavones have no effect on plasma lipid and lipoprotein concentrations in normolipidemic subjects (Nestel et al, 1997; Hodgson et al, 1998). At present, there is no general agreement about the effect of soy protein isoflavones (SPI) on lipid profiles and moreover, it is not clear that which part of the soy protein has lipid-lowering effects. In a study, we designed animal model to assess the effect of SPI on serum lipid, lipoprotein profile, and blood sugar of experimentally- induced hypercholesterolemic rabbits,and to detect any dose-response effect of SPI on the above mentioned variables. In this research, the effect of soy protein containing $200 \mathrm{mg}, 100 \mathrm{mg}$ and a trace amount of both glycoside and aglycone forms of soy isoflavones were assessed in hypercholesterolemic male rabbits. Although the rabbits had a cholesterol-rich diet, the serum total and LDL-cholesterol remained unchanged in the SPI+ group (i.e. intact soy protein diet). The results have indicated that soy protein isoflavones maintained the serum lipid and lipoprotein levels in hypercholesterolemic rabbits kept on a high cholesterol diet, but alcohol-extracted (even half-dose isoflavones) soy protein diets do not have positive effect. Moreover, the hypocholesterolemic effect of isoflavones is not in a dose-response manner and it is suggested that isoflavones activity is closely related to soy protein (Amani et al, 2005).

\subsection{Fiber}

One of the potential ways by which soy protein might exert its effect on blood cholesterol is via its fiber content (about $6 \mathrm{~g}$ as non-starch polysaccharide per $100 \mathrm{~g}$ boiled beans), which is primarily soluble fiber. Soluble fiber (e.g. from oats) has been shown to lower plasma total and LDL-cholesterol, although the effect is small for those consuming moderate amounts (Truswell, 2002). In the meta-analysis by Brown et al. (1999) 2-10 g/day of soluble fiber was associated with a small but significant fall in total cholesterol $(0.045 \mathrm{mmol} / 1$ per $\mathrm{g}$ fiber $)$ and LDL-cholesterol $(0.057 \mathrm{mmol} / \mathrm{l}$ per $\mathrm{g}$ fiber). Three apples or three $(28 \mathrm{~g})$ servings of oatmeal, providing $3 \mathrm{~g}$ soluble fiber, decreased total and LDL-cholesterol by about $0.13 \mathrm{mmol} / \mathrm{l}$. The mechanism of this effect remains undefined. Suggestions include bile acid binding, resulting in an up-regulation of LDL receptors and thus increased clearance of LDL-cholesterol; inhibition of hepatic fatty acid synthesis byproducts of fermentation in the large bowel (e.g. propionate, acetate, butyrate); changes in motility or satiety; or slowed absorption of macronutrients resulting in improved insulin sensitivity (Brown et al., 1999).

Consumption of diets rich in whole-grain cereals (e.g. whole-wheat cereals, whole meal bread and brown rice) has been associated with a lower risk of cardiovascular disease (Pietinen et al., 1996; Jacobs et al., 1999; Liu et al., 1999; Truswell, 2002). Vitamin E, dietary fibre (Richardson, 2000), resistant starch and oligosacchrarides (Cummings et al., 1992), as well as plant sterols (Jones et al., 1997) are some of the components of whole-grain cereals that may contribute to a reduced risk of heart disease (Mc Kevith (2004).

\subsection{Antioxidant}

Vitamins C, E, and B-carotene have antioxidant roles in the body. Vitamin E is the most concentrated antioxidant carried on LDLs and its major function is to prevent oxidation of 
PUFA in the cell membrane (Krummel, 2008). Epidemiologic studies suggest that vitamin E and carotenoids are inversely related to CVD, but randomized trials have not supported these observations (Lee et al., 2005; Lichtenstein et al., 2006). Because data have not shown vitamin $\mathrm{E}$ to be protective, the AHA does not recommend vitamin $\mathrm{E}$ supplementation for CVD prevention (Lichtenstein et al., 2006). However, RRR-a-tocopherol, the natural form of vitamin E, shows promise as an antiinflammatory agent (Gasu et al., 2006). Foods with concentrated amounts of the phytonutrients catechins, have been found to improve vascular reactivity. These foods are red grapes, red wine, tea (especially green tea), chocolate, and olive oil, and should be worked into any CVD preventive eating plan (Kay et al., 2006). In our case - control study, drinking tea was significantly associated with lower risk of coronary events (Amani et al, 2010).

\subsection{Stanols and sterols}

Since the early 1950s plant stanols and sterols isolated from soybean oils or pine tree oil have been known to lower blood cholesterol (Lichtensteine et al., 2001). Recently they have been esterified and made into margarines. Consuming between 2 to $3 \mathrm{~g} /$ day lowers cholesterol by $9 \%$ to $20 \%$ (Lichtenstein et al., 2001). The mechanism for cholesterol lowering is by inhibiting absorption of dietary cholesterol. Adult Treatment Panel III (ATP-III) includes stanols as part of dietary recommendations for lowering LDL cholesterol in adults. Because these esters can also affect the absorption of and cause lower $\beta$-caroten, atocopherol, and lycopene levels, further safety studies are needed for use in normocholesterolemic individuals, children, and pregnant women (Krummel, 2008).

\subsection{Dietary patterns}

The effect on CVD risk of diets rich in whole grains and low in processed foods that are high in fat, sodium, and sugars has increasingly been investigated in both developed and developing countries. In parallel with economic development, radical dietary shifts toward Westernized diets that are high in animal products and refined carbohydrates and low in whole grains and other plant-based foods have occurred in many developing countries. For example in Iran, the results of Amani et al (2010) study showed that daily consumption of vegetable oils, tea and fish is significantly associated with lower risk of coronary events (odds ratio $=0.55(0.31-0.91$ ), $0.3(0.15-0.65), 0.23(0.13-0.42)$, respectively). On the other hand, it was indicated that consumption of hydrogenated fats and full-fat yoghurt is associated with higher risk of coronary artery disease $(\mathrm{OR}=2.12(1.23-3.64)$ and 2.35(1.32-4.18), respectively).

Substantial evidence has accumulated to support the notion that the traditional Mediterranean dietary pattern is protective against CVD. This pattern is characterized by an abundance of fruits, vegetables, whole grain cereals, nuts, and legumes; olive oil as the principal source of fat; moderate consumption of fish and lower consumption of red meat. It is important to note, however, that the dominance in research on the Mediterranean diet has come at the cost of research on other diets commonly consumed around the world that may also have heart health benefits (IOM , 2010).

\subsection{Therapeutic life style change dietary pattern (TLC)}

The ATP-III recommends the TLC dietary pattern for primary and secondary prevention of CHD. AHA recommends diet and lifestyle changes to reduce CVD risk in all people over the age of 2 years (Table 1) (Lichtenstein et al., 2006). SFA recommendations are less than $7 \%$ of calories; total fat content has a range of $25 \%$ to $35 \%$ of calories. 
Consuming $30 \%$ to $35 \%$ of calories from fat while maintaining a low SFA and trans-fatty acid intake is the dietary pattern recommended for individuals with insulin resistance or metabolic syndrome. This higher fat intake, emphasizing PUFAs and monounsaturated fatty acids (MUFA), can be beneficial in lowering triglycerides and raising HDL cholesterol. Also, with a more liberal fat intake, LDL cholesterol can be lowered without exacerbating blood glucose levels. Increasing physical activity and decreasing energy intake to facilitate weight loss are critical to normalize multiple risk factors. Behavioral strategies for weight management to reduce cardiovascular risk have been provided by the AHA (Klein et al., 2004). Learning outcomes include planning meals that fit the TLC plan, reading food labels, modifying recipes, preparing or purchasing appropriate foods, and choosing healthier choices when dining out. Along with the TLC dietary pattern, the Dietary Approaches to Stop Hypertension (DASH) pattern is also appropriate for CVD prevention and treatment . Both of these dietary patterns emphasize grains, cereals, legumes, vegetables, fruits, lean meats, poultry fish, and nonfat dairy products.

Because animal fats provide about two thirds of the SFAs in diet, these foods are limited. High-fat choices are omitted, but low-fat choices can be included. Meat is limited to 5 $\mathrm{oz} /$ day, and eggs to four or fewer per week. Lean meats are high in protein, zinc, and iron; thus, patients who wish to consume meat, a 5-oz portion or less can be fit into the dietary plan if other low SFA choices are made. Neither food group has to be omitted; it is a matter of choice. Most people need to add the recommended two servings of fatty fish per week. Meeting sodium guidelines (1500 to $2300 \mathrm{mg}$ daily) can be a challenge because lower-fat processed foods often contain salt to increase palatability. Patients may need to limit processed foods (Krummel 2008).

\subsubsection{Alcohol}

The global burden of diseases attributable to alcohol has recently been summarized; leading to the conclusion that alcohol is one of the largest avoidable risk factors in low and middle income countries (Rehm et al., 2009). Indeed, WHO estimates that the harmful use of alcohol was responsible for 3.8 percent of deaths and 4.5 percent of the global burden of disease in 2004 (WHO, 2009b). Excessive alcohol intake is associated with increased risk for hypertension, stroke, coronary artery disease, and other forms of CVD; however, there is also a robust body of evidence in a range of populations suggesting light to moderate intake of alcohol may reduce the risk of CHD. Indeed, research suggests that the relationship between alcohol intake and CVD outcomes follows a "J" curve, with the lowest rates being associated with low to moderate intakes of alcohol (Beilin and Puddey, 2006; Lucas et al., 2005). It is important to recognize that, as with any discussion of alcohol and health, the key issues are the quantity of alcohol consumed and the risk or benefit conferred by consumption. Although evidence indicates that low to moderate alcohol use can reduce the risk of CHD, excessive and harmful use clearly increases CVD risk (Beilin and Puddey, 2006; Lucas et al., 2005). It is important that approaches to reduce the burden of CVD not neglect the importance of reducing excessive alcohol consumption.

\subsubsection{Physical activity}

WHO and FAO have highlighted the importance of physical activity as a key determinant of obesity, CVD, and diabetes (Joint WHO/FAO Expert Consultation, 2003). For decades, evidences of the relationship between physical activity and CVD, independent of effects on 
weight and obesity, have been strengthened. Increasing physical activity-including brisk walking - has been shown to decrease the risk of chronic diseases such as CHD, stroke, some cancers (e.g., colorectal and breast cancer), type 2 diabetes, osteoporosis, high blood pressure, and high cholesterol (Physical Activity Guidelines Advisory Committee, 2008)

\section{American Heart Association 2006 Diet Recommendations for Cardiovascular Disease Risk Reduction}

- Balance calorie intake and physical activity to achieve or maintain a healthy body weight.

- Consume a diet rich in vegetables and fruits.

- Choose whole grain, high-fiber foods.

- Consume fish, especially oily fish, at least twice a week.

- Limit intake of saturated fat to $<7 \%$ of energy, trans-fat to $<1 \%$ of energy, and cholesterol to $<300 \mathrm{mg} /$ day by:

- Choosing lean meats and vegetable alternatives.

- Selecting fat-free (skim), $1 \%$-fat, and low-fat dairy products.

- Minimizing intake of partially hydrogenated fats.

- Minimize your intake of beverages and foods with added sugars.

- Choose and prepare foods with little or no salt.

- When consuming alcohol, do so in moderation.

- When eating food that is prepared outside of the home, follow the American Heart Association Diet and Lifestyle Recommendations.

Modified from Lichtenstein AH et al: Diet and lifestyle recommendations revision 2006: a scientific statement from the American Heart Association Committee, Circulation 114:83, 2006.

Table 1.

Regular physical activity and higher cardiorespiratory fitness are associated with lower overall mortality from CVD. Men and women who are physically active experience a lower risk of cardiovascular disease in general and CHD in particular (US Department of Health 
and Human Services, 1996; Wannamethee \& Shaper, 2002). Furthermore, in the Nurses' Health Study, a large prospective study in the USA, both brisk walking and regular vigorous exercise were associated with a reduction in risk of coronary events by $30-40 \%$ (Manson et al., 1999), and sedentary women who became active in middle age or later had a lower risk than their counterparts who remained sedentary . In one study performed among 145 women with central obesity, serum concentration of HDL-c was significantly higher in women who do more physical activity (Sharifi et al,2008). With overall mortality, the epidemiological literature for $\mathrm{CHD}$ indicates an inverse association and a dose response gradient between physical activity level or cardiorespiratory fitness and incidence of CHD. It helps to improve several risk factors for cardiovascular disease, including raised blood pressure, adverse blood lipid profile and insulin resistance.

\subsubsection{Related diseases/syndrome}

\subsubsection{Overweight and obesity}

Traditionally, obesity is defined as a BioPsychoSocial problem but in this chapter we rather intend to present it as an EcoBioPsychoSocioCutural issue.

Overweight and obesity have reached epidemic proportions, not only in developed but also in developing countries (Sassi et al., 2009). Even in low and middle income countries where undernutrition is still highly prevalent, overweight and obesity-especially among women - is a public health problem (Caballero, 2005; Hosseinpanah et al 2009). WHO and FAO reviewed the evidence on the relationship between obesity and the risk of CVD and concluded that overweight and obesity confer a significantly elevated risk of CHD (Joint WHO/FAO Expert Consultation, 2003). Increased body mass index (BMI) is also associated with greater risk of stroke in both Asian and Western populations (WHO/FAO, 2003). The association between obesity and CVD is partly mediated through hypertension, high cholesterol, and diabetes. Abdominal or central obesity measured by waist-to-hip ratio or waist circumference is associated with both CHD and stroke independent of BMI and other cardiovascular risk factors. Even in university educated women, obesity and central fat are also prevalent which increase the risk of heart disease. We studied 101female staff of the university, aged 20-45 years. Based on the bioelectrical impedance analysis (BIA) method, overweight and obesity rates were determined in 34.6 and 40.6 percent of women, respectively, and central obesity was prevalent in $27 \%$ of them (Amani, 2007a). It is worthy to note that to prevent erroneous classification, localization of cut-off points can be a more practical way to detect individuals at greater risk of chronic disease. In a sample of 637 married females, it was indicated that subjects in low BMI range tend to have higher fat percentages and they might represent a different category as overfat thin other than normal weight obese in Iranian women. (Amani, 2007b).

Obesity is also an independent risk factor for other cardiovascular outcomes, such as congestive heart failure and sudden cardiac death. Excess energy intake is one of the key contributors to obesity. The lack of data limits policy makers' abilities to focus attention on which dietary components lend to effective interventions that would reduce total calorie intake. One category that has been well studied in developed countries relates to sugar consumption, primarily in the form of sugar-sweetened beverages (including soft drinks, 
juice drinks, and energy and vitamin drinks). Recent NHANES data shows that up to 5.5 percent of dietary calories come from sugar-sweetened beverages in the United States (Bosire et al., 2009), which has led the American Heart Association to recommend an upper limit of 100 calories per day for women and 150 calories per day for men from added sugars, including soft drinks (Johnson et al., 2009). In some developing countries, consumption of sugar-sweetened beverages has increased dramatically in recent decades. Because of its excess caloric and sugar content, increasing consumption of sugar sweetened beverages may have important implications for obesity and cardiometabolic risk.

\subsubsection{Hypertension}

Hypertension is a risk factor for CHD, stroke, and heart failure. A recent review of the global burden of high blood pressure found that approximately 54 percent of stroke, 47 percent of IHD and 25 percent of other CVDs were attributable to hypertension. Among the major underlying risks for hypertension are sodium, body weight, and access to treatment. Primary prevention focused on sodium reduction, fruit and vegetable intake, weight control, and avoidance of excessive alcohol intake has been shown to make a difference (Krummel, 2008).

\subsubsection{Diabetes}

Around the world, diabetes is increasingly growing and is a significant contributor to CVD risk. People with diabetes have more than two-fold greater risk of CVD compared to nondiabetics (Asia Pacific Cohort Studies Collaboration, 2003). In fact, CVD is the leading cause of morbidity and mortality in people with diabetes (Booth et al., 2006; Kengne et al., 2007, 2009). Individuals without established clinical diabetes, but who are at increased risk of developing diabetes in the future, also have a higher risk of CVD (Asia Pacific Cohort Studies Collaboration, 2007). Women and younger individuals with diabetes have greater risk of CVD. Obesity is the single most important risk factor for type 2 diabetes, but unhealthy diet and physical inactivity also independently raise the population risk for diabetes (Schulze and $\mathrm{Hu}, 2005)$. According to the International Diabetes Federation's Diabetes Atlas 2010, the global estimated prevalence of diabetes for 2010 among people aged 20 to 79 years will be approximately 285 million people (6.4 percent of the global population), of which some 70 percent will be living in developing countries (International Diabetes Federation, 2010).

Diabetes is emerging as a particular concern in Asia, where more than 110 million individuals were living with diabetes in 2007, a large proportion of whom were young and middle aged. Asians tend to develop diabetes at a relatively young age and low BMI, and by 2025 the number of individuals with diabetes in the region is expected to rise to almost 180 million (Chan et al., 2009). Intensive glucose control reduces the risk of major cardiovascular events by approximately 10 percent, compared with standard treatment in people with diabetes. Interestingly, this benefit appeared to be independent of other cardiovascular risk factors (Kelly et al., 2009; Turnbull et al., 2009).

To sum up, as with the raising obesity epidemic, the prevalence of diabetes has increased dramatically worldwide. It is associated with serious health consequences and is a major risk factor for $\mathrm{CHD}$ and stroke. Therefore, prevention and management of diabetes are critical in reducing the global burden of CVD. 


\subsubsection{Psychosocial risk and mental health}

Of all the psychosocial stressors associated with CVD, the link between depression and CVD is probably the best documented. There have been many published reviews and numerous meta-analyses have consistently found that depression and depressive symptoms are associated with an increased likelihood of developing CVD, a higher incidence of CVD events, poorer outcomes after CVD treatment and prevention efforts, and increased mortality from CVD. These associations remain consistent even after controlling for other CVD risk factors (Everson-Rose and Lewis, 2005; Frasure-Smith and Lesperance, 2006; Lesperance and Frasure-Smith, 2007; Lichtman et al., 2008).

Behaviors that increase CVD risks are more common in depressed patients. They are more likely to smoke, have poor diets, and be physically inactive. Furthermore, depression has been found to associate with the risk of non adherence to medical treatment regimens and lifestyle changes, making depressed patients with CVD or high CVD risk less likely to adhere to prevention efforts (Lichtman et al., 2008; Ziegelstein et al., 2000).

Chronic stress, most often studied by examining work-related stress, has been associated with negative behaviors such as low physical activity and poor diet, increased likelihood of recurrent CVD, as well as physiological consequences such as decreased heart rate variability. For instance, we found that the prevalence of overweight and obesity was higher in a sample of firefighters who may have chronic stress. Moreover they had high TC, TG and lipoprotein (a) and low HDL-C concentrations (Azabdaftari et al, 2009).

Acute stress from traumatic life events such as the death of a relative, earthquakes, or terrorist attacks have all been associated with significant temporal increases in the incidence of MI (Everson-Rose and Lewis, 2005; Figueredo, 2009).

It is clear that psychosocial factors play an important role in increasing CVD risk through both direct and indirect pathways. Continued research is needed to further explain the mechanisms by which psychosocial stressors and mental illness affect CVD risk. It is also important that clinicians are made aware of the effect of psychosocial factors on CVD risk, prognosis, and adherence to prevention efforts through improved training and knowledge expanding.

\subsection{Nonmodifiable factors}

\subsubsection{Menopausal status}

Loss of estrogen following natural or surgical menopause is associated with increased CVD risk. Endogenous estrogen has a protective role against CVD in premenopausal women, probably by preventing vascular injury. Rates of CHD in premenopausal women are low except in women with multiple risk factors. During the menopausal period total cholesterol, LDL cholesterol, and triglyceride levels increase; and HDL cholesterol level decreases, especially in women who are overweight or obese (Regitz-Zagrosek, 2006).

\subsubsection{Age and gender}

Age is a nonmodifiable risk factor for CHD. The increased risk for CHD parallels increase in age. Higher mortality rates from CHD are seen in both genders with increasing age. 
Being older than 45 years of age is considered a risk factor for men (NCEP, 2002). For women the increased risk comes after the age of 55 years, which is after menopause for most women.

CVD prevalence, incidence, and mortality rates tend to be higher for men than for women. This finding has remained consistent historically (Lawlor et al., 2001) and across countries and regions (Allen and Szanton, 2005; Pilote et al., 2007; WHO, 2009).

Estrogen has a protective effect on the development of CVD risk factors and consequently is the reason most often cited for these gender differences (Regitz-Zagrosek, 2006). Estrogen is thought to contribute to premenopausal women's tendency to have lower systolic blood pressure, higher levels of HDL cholesterol, and lower triglyceride levels than men ( Pilote et al., 2007).

The lower prevalence of smoking among women is another factor that could contribute to their decreased CVD incidence and mortality rates. Around the world, the prevalence of female smoking is lower than that of men (Pilote et al., 2007). Although rates of smoking, dyslipidemia, and hypertension are generally lower among women than men, women tend to have less favorable profiles for other key CVD risk factors. Worldwide, women are more likely to be sedentary than men (Guthold et al., 2008). Some researchers have suggested that women's social status in many cultures and their lack of leisure time due to childcare and other familial responsibilities likely contribute to their lower levels of physical activity (Brands and Yach, 2002; Pilote et al., 2007).

Another troubling gender difference is the increased prevalence of obesity among women. WHO data indicate that although overweight (BMI $\geq 25 \mathrm{~kg} / \mathrm{m} 2$ ) is more common among men globally; obesity (BMI $\geq 30 \mathrm{~kg} / \mathrm{m} 2$ ) is more common among women.

A number of different reasons have proposed by CVD researchers that why women might delay seeking medical attention, receive delayed treatment, and experience poorer outcomes during and after an MI or stroke. One often-cited reason that women tend to wait longer to seek treatment is that many do not perceive themselves as being at risk (Jensen and Moser, 2008).

Because of the robust evidence indicating gender differences in CVD incidence, morbidity, and outcomes, these differences, as well as the unique needs of women, should be considered when developing CVD research priorities, policies, and health service interventions.

\section{Association between early life factors and subsequent risk for CVD}

\subsection{Low birth weight and adult cardiovascular disease}

Ther is growing evidence in developing and developed countries ,based on cohort studies, that fetal and early childhood periods is important in the onset of CVD later in life (Victora et al., 2008; Walker and George, 2007; WHO, 2009c). The influences during this period include maternal factors during pregnancy, such as smoking, obesity, and malnutrition, and factors in infancy and early childhood, such as breastfeeding, low birth weight, and undernutrition. 
Maternal smoking during pregnancy has been linked to CVD-related risk factors. It has been consistently associated with increased childhood obesity independent of other risk factors (Oken et al., 2008). A number of studies have examined the effects of maternal obesity on the body weight of their children; however, the evidence is inconsistent. Two cohort studies in the United States found that excessive weight gain or maternal obesity during pregnancy was associated with overweight and obesity in the children at ages 3 and 4 years (Gillman et al., 2008; Whitaker,2004). Similarly, a cohort study in Finland found that mothers' body mass index (BMI) was positively associated with their sons' BMI in childhood (Eriksson et al., 1999).

Another factor that appears to influence risk for long-term cardiovascular health is breastfeeding. Breastfeeding has been found to not only reduce childhood morbidity and mortality but also to be weakly protective against obesity later in life (Bhutta et al., 2008; Gluckman et al., 2008).

Undernutrition in infancy, especially when followed by rapid weight gain, is associated with increased risk of CVD and diabetes in adulthood (Barker and Bagby, 2005; Caballero, 2005; Gluckman et al., 2008 ). This phenomenon is known as the developmental origins theory of CVD. It means that if disruptions to the nutritional, metabolic, and hormonal environment at critical stages of development are happened, it may lead to permanent "programming" of the body's structure, physiology, and metabolism that translate into pathology and disease, including CVD, later in life (Barker, 1997, 1998, 2007). The exact physiological mechanisms through which this programming occurs are not yet fully elucidated; however, there is evidence that fetal and early postnatal undernutrition can cause metabolic, anatomic, and endocrine adaptations that affect the hypothalamicpituitary-adrenal axis, lipoprotein profiles, and end organ glucose uptake, among other processes (Prentice and Moore, 2005). Support for the developmental origins theory of CVD comes from a number of retrospective, and more recently prospective, cohort studies in various populations. Studies in the United Kingdom, the United States, Finland, and India found that fetal undernutrition followed by a rapid catch-up growth from childhood to early adolescence was significantly associated with the later development of CVD in both men and women (Barker et al., 2005; Eriksson et al., 1999; Osmond and Barker, 2000). Early undernutrition followed by catch-up growth during childhood has also been associated with subsequent hypertension and type 2 diabetes (Barker, 1998; Osmond and Barker, 2000) This emerging data on the effects of rapid weight gain after early undernutrition have prompted some researchers to suggest a shift from the original "fetal origins" hypothesis to an "accelerated postnatal growth hypothesis" of CVD (Singhal et al., 2003, 2004).

The emerging evidence on the association between low birth weight followed by rapid growth in childhood and subsequent risk for CVD raises important considerations for addressing global CVD because low birth weight and exposure to undernutrition in utero and in infancy are common in many developing countries (Caballero, 2009; Kelishadi, 2007).

The acquisition and accumulation of risk for CVD continues in childhood and adolescence (Celermajer and Ayer, 2006 ). Unhealthful lifestyle practices such as consumption of high calorie and high fat foods, tobacco use, and physical inactivity begin in childhood, introducing major behavioral risks for CVD. Childhood adversity also influences adult cardiovascular health. In addition, there is also an emerging body of evidence on the 
presence of biological risk factors in children and youth, including pathophysiological processes associated with heart disease that can be seen as early as childhood.

\subsection{Childhood obesity and CVD risk}

Childhood obesity is associated with multiple risk factors for CVD, which are amplified in the presence of overweight and persist from childhood into adulthood. These risk factors include hyperlipidemia, high blood pressure, impaired glucose tolerance and high insulin levels, as well as metabolic syndrome. It has been estimated that 60 percent of overweight children possess at least one of these risk factors that can lead to CVD in adulthood (Freedman et al., 1999). This is especially important in terms of implications for global CVD because the prevalence of childhood obesity is increasing in developing countries (WHO, 2008a).

\section{Public health approach to cardiovascular disease risk reduction}

\subsection{Cardiovascular disease as a public health problem}

The prevention of cardiovascular disease is a major public health challenge for a number of years around the world. Although death rates have been falling in many westernized countries (e.g. USA, Australia, UK), rates are rising rapidly elsewhere.

\subsection{Current dietary recommendations for primary prevention}

Dietary recommendations tend to be country specific and are based on the available evidence.

The ATP-III recommends the TLC dietary pattern for primary and secondary prevention of CHD. In agreement, the AHA recommends diet and lifestyle changes to reduce CVD risk in all people over the age of 2 years (Lichtenstein et al., 2006).

As is evident, knowledge about the role of diet in risk factor reduction and reducing the risk of cardiovascular events themselves continues to expand. It is now recognized that CVD risk can be mediated through multiple biological pathways other than only serum total and LDL cholesterol or dietary factors. With this in mind, it is necessary to modify the dietary advice offered to those with an increased risk of CVD.

\subsection{Health promotion in children and other subgroups of the population}

Health aspects present in childhood, such as blood lipids, body weight and blood pressure may track into adulthood. Therefore, a useful health strategy is the adoption of sensible eating habits and an active lifestyle early in childhood. It is important to promote cardiovascular health in childhood by increasing physical activity and preventing or treating obesity, raised blood pressure, insulin resistance and type 2 diabetes (Williams et al., 2002). Current nutritional recommendations for the general population are applicable for most children over 5 years and can be gradually applied from the age of 2 years. It is also recommended that all children and adolescents participate in physical activity for 1 hour daily which should be of at least moderate intensity (Fox \& Riddoch, 2000). The implementation of guidelines and success of health strategies require input from the 
governments, health professionals, the food industry and teachers, as well as the children themselves and their parents. Moreover, social and cultural influences must be recognized when designing and implementing strategies.

\section{Summary}

- Cardiovascular disease is the leading cause of death worldwide, accounting for around 18 million deaths each year.

- Modifiable risk factors for cardiovascular disease include atherogenic lipoproteins, inflammatory related factors behaviors, lifestyle and chronic diseases such as obesity, diabetes and hypertension.

- Non modifiable risk factors include menopause, age and gender.

- There is evidence that a chronic, low-grade inflammation underlies atherosclerosis, although it is not clear whether this is a cause or effect phenomenon.

- The acute phase proteins, C-reactive protein (CRP), fibrinogen and serum amyloid A, appear to be associated with risk for cardiovascular disease.

- The advantages of a dietary pattern approach rather than individual dietary components can influence plasma cholesterol levels and may also affect other emerging risk factors.

- Physical activity has great impact on CVD risk reduction when it is accompanied by dietary pattern changes.

- Low birth weight and low weight gain during infancy are associated with an increased risk of adult cardiovascular disease, hypertension, type 2 diabetes and the insulin resistance syndrome.

\section{Future research}

Future research is required to establish the strength of the associations between the emerging risk factors described in this chapter and cardiovascular disease, in order to compare their predictive value with the established risk factors. For example, further work is required to evaluate the independence of many of the novel risk factors for cardiovascular disease and whether these associations are causal. In addition, more information is needed about how these novel risk factors might be modified by different aspects of the diet. As indicated in ancient Traditional Persian Medicine (TPM), understanding the effect of individual foods on the trend of heart disease and hyperlipidemias can be leading fields of study in the near future.

Moreover, local modified risk factors should be defined and addressed to track the patients at greater risks in more applicable ways.

\section{References}

Allen, J., \& S. Szanton. 2005. Gender, ethnicity, and cardiovascular disease. Journal of Cardiovascular Nursing 20(1):1-6; quiz 7-8.

Amani R, Baghdadchi J \& Zand-Moghaddam A, 2005. Effects of Soy Protein Isoflavones on Serum Lipids, Lipoprotein Profile and Serum Glucose of Hypercholesterolemic Rabbits. Int J Endocrinol Metab ; 2:87-92. 
Amani R, noorizadeh M, Rahmanian S, Afzali N \& Haghighizadeh M, 2010. Nutritional related cardiovascular risk factors in patients with coronary artery disease in IRAN:A case-control study. Nutrition Journal, 9:70.

Reza Amani, Fereshteh Boustani. 2007 a. Prevalence of obesity and dietary practices in Jondi-Shapour University female personnel, Ahvaz, Iran Pak J Med Sci;24(4):748-52.

Amani R, 2007 b. Comparison between bioelectrical impedance analysis and body mass index methods in determination of obesity prevalence in Ahvazi women. Eur J Clin Nutr ;61(4): 478-82.

Anber V, Millar JS, McConnell M, Shepherd J, Packard CJ\& 1997. Interaction of very-lowdensity, intermediatedensity, and low-density lipoproteins with human arterial wall proteoglycans. Arteriosclerosis, Thrombosis and Vascular Biology, 17, 2507-14.

Anderson JW, Johnstone BM and Cook-Newell ME \& 1995. Meta-analysis of the effects of soy protein intake on serum lipids. N Engl J Med. 3;333(5):276-82.

Anerson JJB, Anthony M, Messina M \& Garner SC, 1999. Effects of phyto-oestrogens on tissues. Nutr Res Rev. 12: 75-116.

Anthony MS, Clarkson TB, Hughes CL Jr, Morgan TM \& Burke GL, 1996. Soybean isoflavones improve cardiovascular risk factors without affecting the reproductive system of peripubertal rhesus monkeys. J Nutr. 126(1):43-50.

Arora A, Nair MG \& Strasburg GM, 1998. Antioxidant activities of isoflavones and their biological metabolites in a liposomal system. Arch Biochem Biophys. 356(2):133-41.

Asia Pacific Cohort Studies Collaboration. 2003. The effects of diabetes on the risks of major cardiovascular diseases and death in the Asia Pacific region. Diabetes Care 26(2): 360-366.

Asia Pacific Cohort Studies Collaboration. 2007. Cholesterol, diabetes and major cardiovascular diseases in the Asia-Pacific region. Diabetologia 50(11):2289-2297.

Astrup A ,2002. Dietary fat is a major player in obesity - but not the only one. Obesity Reviews, 3, 57-8.

Aygun A D et al,2005. Proinflammatoy cytokines and leptin are increased in serum of prepubertal obese children, Mediators Inflamm $3: 180$.

Azabdaftari N, Amani R, Taha Jalali M, 2009. Biochemical and nutritional indices as cardiovascular risk factors among Iranian firefighters. Ann Clin Biochem. Sep;46(Pt 5):385-9

Barker, D. J. 1997. The fetal origins of coronary heart disease. Acta Paediatrica Supplement 422:78-82.

Barker, D. J. P. 1998. In utero programming of chronic disease. Clinical Science 95(2): 115-128.

Barker, D. J. P., \& S. P. Bagby. 2005. Developmental antecedents of cardiovascular disease: A historical perspective. Journal of the American Society of Nephrology 16(9): 2537-2544.

Barker, D. J. P. 2007. The origins of the developmental origins theory. Journal of Internal Medicine 261(5):412-417.

Basu A et al,2006: Dietary factors that promote or retard inflammation, Arterioscler Thromb Vasc Biol, 26:995.

Beilin, L. J., \& I. B. Puddey. 2006. Alcohol and hypertension: An update. Hypertension 47(6):1035-1038. 
Bhutta, Z. A., T. Ahmed, R. E. Black, S. Cousens, K. Dewey, E. Giugliani, B. A. Haider, B.Kirkwood, S. S. Morris, H. P. S. Sachdev, \& M. Shekar. 2008. What works? Interventions for maternal and child undernutrition and survival. Lancet 371(9610):417-440.

Blum CA et al,2005. Low-grade inflammation and estimates of insulin resistance during the menstrual cycle in lean and overweight women. J Clin Endocrinol Metab 90:3230.

Booth, G. L., M. K. Kapral, K. Fung, \& J. V. Tu. 2006. Recent trends in cardiovascular complications among men and women with and without diabetes. Diabetes Care 29(1):32-37.

Bosire, C., J. Reedy, \& S. M. Krebs-Smith. 2009. Sources of energy and selected nutrient intakes among the US population, 2005 -06 : A report prepared for the 2010 dietary guidelines advisory committee. Bethesda, MD: National Cancer Institute.

Brands, A., \& D. Yach. 2002. Women and the rapid rise of noncommunicable diseases.World Health Organization NMH Reader (1):1-22.

Brown L, Rosner B, Willett WW\& Sacks FM 1999.) Cholesterol lowering effects of dietary fibre: a meta-analysis.

Buckley DI, Fu R, Freeman M, Rogers K \& Helfand M. (2009). C-reactive protein as a risk factor for coronary heart disease: a systematic U.S. Preventive Services Task Force. Ann Intern Med , 151, 483-495.

Caballero, B. 2005. A nutrition paradox - underweight and obesity in developing countries. New England Journal of Medicine 352(15):1514-1516.

Caballero, B. 2009. Early undernutrition and risk of CVD in the adult. Presentation at Public Information Gathering Session for the Institute of Medicine Committee on Preventing the Global Epidemic of Cardiovascular Disease, Washington, DC.

Celermajer, D. S., \& J. G. Ayer. 2006. Childhood risk factors for adult cardiovascular disease and primary prevention in childhood. Heart 92(11):1701-1706.

Chait A, Brazg RL, Tribble DL \& Krauss RM ,1993. Susceptibility of small, dense, low-density lipoproteins to oxidative modification in subjects with the atherogenic lipoprotein phenotype, pattern B. American Journal of Medicine, 94, 350-6.

Chan, J. C., V. Malik, W. Jia, T. Kadowaki, C. S. Yajnik, K. H. Yoon, F. B. \& Hu. 2009. Diabetes in Asia: Epidemiology, risk factors, and pathophysiology. Journal of the American Medical Association 301(20):2129-2140.

Chen , L. Y. , \& J. L. Mehta . 1994 . Inhibitory effect of high-density lipoprotein on platelet function is mediated by increase in nitric oxide synthase activity in platelets. Life Sci. 55 : 1815 - 1821 .

Critchley, J., J. Liu, D. Zhao, W. Wei, and S. Capewell. 2004. Explaining the increase in coronary heart disease mortality in Beijing between 1984 and 1999. Circulation 110(10):1236-1244.

Cummings J, Bingham S, Heaton K, Eastwood M ,1992. Fecal weight, colon cancer risk and dietary intake of non-starch polysaccharide (dietary fibre). Gastroenterology, 103, 1783-7.

Danesh J, Whincup P, Walker M et al. ,2000. Low grade inflammation and coronary heart disease: prospective study and update meta-analyses. British Medical Journal, 321, 199-203. 
Davies, A. R., L. Smeeth, and E. M. Grundy. 2007. Contribution of changes in incidence and mortality to trends in the prevalence of coronary heart disease in the UK: 19962005. European Heart Journal 28(17):2142-2147.

Davignon J, Ganz P, 2004. Role of endothelial dysfunction in atherosclerosis. Circulation ,109(23 suppl |):III27.

Dejager S, Bruckert E, Chapman MJ ,1993. Dense low density lipoprotein subspecies with diminished oxidative resistance predominate in combined hyperlipidaemia. Journal of Lipid Research, 34, 295-308.

de Lorgeril $\mathrm{M}$ et al,1999: Mediterranean diet, traditional risk factors, and the rate of cardiovascular complications after myocardial infarction, Circulation, 99 :779.

D'Erasmo E, Acca M, Celi F, Medici F, Palmerini T and Pisani D,1993. Plasma fibrinogen and platelet count in stroke. J Med;24:185-191.

Dreon DM, Fernstrom HA, Miller B, Krauss RM, 1994. Low-density lipoprotein subclass patterns and lipoprotein response to a reduced-fat diet in men. FASEB Journal, 8, 121-6.

Eriksson, J. G., T. Forsen, J. Tuomilehto, P. D. Winter, C. Osmond, and D. J. P. Barker. 1999. Catch-up growth in childhood and death from coronary heart disease: Longitudinal study. British Medical Journal 318:7181.

Everson-Rose, S. A., and T. T. Lewis. 2005. Psychosocial factors and cardiovascular diseases. In Annual Review of Public Health 26(1):469-500.

Figueredo, V. M. 2009. The time has come for physicians to take notice: The impact of psychosocial stressors on the heart. American Journal of Medicine 122(8):704-712.

Foster, R. K., and H. E. Marriott. 2006. Alcohol consumption in the new millenniumweighing up the risks and benefits for our health. Nutrition Bulletin 31(4):286-331.

Fox KR, Riddoch CJ (2000) Charting the physical activity patterns of contempory children and adolescents. Proceedings of the Nutrition Society, 59, 497-504.

Frasure-Smith, N., and F. Lesperance. 2006. Recent evidence linking coronary heart disease and depression. Canadian Journal of Psychiatry-Reoue Canadienne de Psychiatrie 51(12):730-737.

Frayn $\mathrm{K}$,2005. Cardiovascular disease diet, nutrition and emerging risk factors. Blackwell Publishing. Oxford,UK.

Gao X et al,2004. Plasma C-reactive protein and homosysteine concentrations are related to frequent fruit and vegetable intake in Hispanic and non-Hispanic white elders . J Nutr ,134:913.

Gebauer SK et al, 2006. n-3 fatty acid dietary recommendations and food sources to achieve essentiality and cardiovascular benefits. Am J Clin Nutr 83(6 suppl):15262s.

Gillman, M. W., S. L. Rifas-Shiman, K. Kleinman, E. Oken, J. W. Rich-Edwards, and E. M. Taveras. 2008. Developmental origins of childhood overweight: Potential public health impact. Obesity 16(7):1651-1656.

Gluckman, P. D., M. A. Hanson, A. S. Beedle, and D. Raubenheimer. 2008. Fetal and neonatal pathways to obesity. In Frontiers of hormone research. Vol. 36. Edited by M. Korbonits. Basel: Karger. Pp. 61-72.

Gotoh K et al, 2006. Apolipoprotein A -IV interacts synergistically with melanocoftins to reduce food intake, Am J Physiol Regul Integr Comp Physiol 290 :R202. 
Gritz, E. R., D. J. Vidrine, and M. Cororve Fingeret. 2007. Smoking cessation. A critical component of medical management in chronic disease populations. American Journal of Preventive Medicine 33(6 Suppl):S414-S422.

Guthold, R., T. Ono, K. L. Strong, S. Chatterji, and A. Morabia. 2008. Worldwide variability in physical inactivity - a 51-country survey. American Journal of Preventive Medicine 34(6):486-494.

Hadaegh F, Harati H, Ghanbarian A, Azizi F 2009. Prevalence of coronary heart disease among Tehran adults: Tehran Lipid and Glucose Study. East Mediterr Health J.;15(1):157-66.

He, F. J., and G. A. MacGregor. 2009. A comprehensive review on salt and health and current experience of worldwide salt reduction programmes. Journal of Human Hypertension 23(6):363-384.

Hodgson JM, Puddey IB, Beilin LJ, Mori TA and Croft KD,1998. Supplementation with isoflavonoid phytoestrogens does not alter serum lipid concentrations: a randomized controlled trial in humans. J Nutr.;128(4):728-32.

Hosseinpanah F, Barzin M, Eskandary PS, Mirmiran P, Azizi F, 2009. Trends of obesity and abdominal obesity in Tehranian adults: a cohort study.BMC Public Health. 23;9:426.

$\mathrm{Hu}$, F. B. 2008. Globalization of food patterns and cardiovascular disease risk. Circulation 118(19):1913-1914.

IDF (International Diabetes Federation). 2006. The diabetes atlas. Brussels: IDF.

IDF. 2010. The diabetes atlas. Brussels: IDF.

IOM (Institute of Medicine). 2009. Secondhand smoke exposure and cardiovascular effects: Making sense of the evidence. Washington, DC: The National Academies Press.

IOM. 2010. Promoting Cardiovascular Health in the Developing World: A Critical Challenge to Achieve Global Health. Washington, DC: The National Academies Press.

Jacobs DR, Meyer KA, Kushi LH, Folsom AR ,1999. Is whole grain intake associated with reduced total and cause-specific death rates in older women? The Iowa Women's Health Study. American Journal of Public Health, 89, 322-9.

Jensen, L. A., and D. K. Moser. 2008. Gender differences in knowledge, attitudes, and beliefs about heart disease. Nursing Clinics of North America 43(1):77-104; vi-vii.

Jequier, E. 1999. Alcohol intake and body weight: A paradox. American Journal of Clinical Nutrition 69(2):173-174.

Jha, P., and F. J. Chaloupka. 1999. Curbing the epidemic: Governments and the economics of tobacco control. Washington, DC: World Bank.

Johnson, R. K., L. J. Appel, M. Brands, B. V. Howard, M. Lefevre, R. H. Lustig, F. Sacks, L. M. Steffen, J. Wylie-Rosett, P. A. American Heart Association Nutrition Committee of the Council on Nutrition, Physical Activity, and Metabolism, and the the Council on Epidemiology and Prevention. 2009. Dietary sugars intake and cardiovascular health: A scientific statement from the American Heart Association. Circulation 120(11):1011-1020.

Joint WHO/FAO Expert Consultation on Diet Nutrition and the Prevention of Chronic Diseases and World Health Organization Department of Nutrition for Health and Development.2003. Diet, nutrition and the prevention of chronic diseases: Report of a 
joint WHO/FAO expert consultation, Geneva, January- February 2002, WHO technical report series. Geneva: World Health Organization.

Jones PJ, MacDougall DE, Ntanios F, Vanstone CA ,1997. Dietary phytosterols as cholesterollowering agents in humans. Canadian Journal of Physiology and Pharmacology, 75, 217-27.

Joseph A, Kutty VR and Soman CR ,2000. High risk for coronary heart disease in Thiruvananthapuram City: A study of serum lipids and other risk factors. Indian Heart J 2000, 52:29-35.

Karmally W, 2005. Balancing unsaturated fatty acids: what is the evidence for cholesterol lowering ?J Am Diet assoc 105:1068.

Kay CD et al, 2006. Effects of antioxidant rich foods on vascular reactivity review of the clinical evidence Curr Atheroscer Rep 8:510.

Kelishadi, R. 2007. Childhood overweight, obesity, and the metabolic syndrome in developing countries. Epidemiologic Reviews 29:62-76.

Kelly, T. N., L. A. Bazzano, V. A. Fonseca, T. K. Thethi, K. Reynolds, and J. He. 2009. Glucose control and cardiovascular disease in type 2 diabetes. Annals of Internal Medicine 151(6):1-10.

Kengne, A. P., A. Patel, F. Barzi, K. Jamrozik, T. H. Lam, H. Ueshima, D. F. Gu, I. Suh, and M. Woodward. 2007. Systolic blood pressure, diabetes and the risk of cardiovascular diseases in the Asia-Pacific region. Journal of Hypertension 25(6):1205-1213.

Kengne, A. P., K. Nakamura, F. Barzi, T. H. Lam, R. Huxley, D. Gu, A. Patel, H. C. Kim, and M. Woodward. 2009. Smoking, diabetes and cardiovascular diseases in men in the Asia Pacific region. Journal of Diabetes 1(3):173-181.

Klein S et al, 2004. Clinical implications of obesity with specific focus on cardiovascular disease :a statement for professionals from the American Heart association Council on Nutrition, Physical Activity, and Metabolism: endorsed by the American College of Cardiology Foundation, Circulation 110; 2952.

Krummel DA 2008. Medical nutrition therapy for cardiovascular disease, In: Krauses food $\mathcal{E}$ nutrition therapy (2008). Mahan K \& Scott-Stump S,pp(833-864) 12th ed. Philadelphia: Saunders; ISBN: 978-1-4160-3401-8

Lamarche B, St-Pierre AC, Ruel IL, Cantin B, Dagenais GR, Despres JP, 2001. A prospective, population based study of low density lipoprotein particle size as a risk factor for ischemic heart disease in men. Can J Cardiol; 17:859-65.

Lawlor, D. A., S. Ebrahim, and G. Davey Smith. 2001. Sex matters: Secular and geographical trends in sex differences in coronary heart disease mortality. British Medical Journal 323(7312):541-545: Erratum 325(7364):580.

Lesperance, F., and N. Frasure-Smith. 2007. Depression and heart disease. Cleveland Clinic Journal of Medicine 74(Suppl 1):S63-S66.

Lichtenstein AH,1998. Soy protein, isoflavones and cardiovascular disease risk. J Nutr. Oct;128(10):1589-92.

Lichtenstein AH et al,2001. Stanol/steroel ester-containing foods and blood cholesterol levels, Circulation 103:1177.

Lichtenstein AH et al, 2006. Diet and lifestyle recommendations revision 2006: a scientific statement from the American Heart Association Nutrition Committee, Circulation 114:82. 
Lichtman, J. H., J. T. Bigger Jr., J. A. Blumenthal, N. Frasure-Smith, P. G. Kaufmann, F. Lesperance, D. B. Mark, D. S. Sheps, C. B. Taylor, and E. S. Froelicher. 2008. Depression and coronary heart disease: Recommendations for screening, referral, and treatment-a science advisory from the American Heart Association Prevention Committee of the Council on Cardiovascular Nursing, Council on Clinical Cardiology, Council on Epidemiology and Prevention, and Interdisciplinary Council on Quality of Care and Outcomes Research. Circulation 118(17):1768-1775.

Liu S, Stampfer MJ, Hu FB et al. ,1999. Whole-grain consumption and risk of coronary heart disease: results from the Nurses' Health Study. American Journal of Clinical Nutrition, 70, 412-9.

Lominadze D, Joshua I and Schuschke D, 1998. Increased erythrocyte aggregation in spontaneously hypertensive rats. Am J Hypertens;11:784-789.

Lominadze D, Dean WL, Tyagi SC and Roberts AM, 2010. Mechanisms of fibrinogen-induced microvascular dysfunction during cardiovascular disease. Acta Physiol ;198(1): 1-13.

Lopez, A. D., C. D. Mathers, M. Eszati, D. T. Jamison, and C. J. L. Murray. 2006. Global burden of disease and risk factors. Washington, DC: World Bank.

Lucas, D. L., R. A. Brown, M. Wassef, and T. D. Giles. 2005. Alcohol and the cardiovascular system research challenges and opportunities. Journal of the American College Cardiology 45(12):1916-1924.

Manson JE, Hu FB, Rich-Edwards JW et al. ,1999. A prospective study of walking as compared with vigorous exercise in the prevention of CHD in women. New England Journal of Medicine, 341(9), 650-8.

McKevith B ,2004. Nutritional aspects of cereals. Nutrition Bulletin, 29, 111-42.

Mensink RP et al, 2003. Effects of dietary fatty acids and carbohydrates on the ratio of serum total to HDL cholesterol and on serum lipids and apolipoproteins a: meta-analysis of 60 controlled trials, Am J Clin Nutr $77: 1146$.

Mozaffarian D, Abdollahi M, Campos H, Houshiarrad A, Willett WC, 2007. Consumption of trans fats and estimated effects on coronary heart disease in Iran. Eur J Clin Nutr, 61(8):1004-10.

Mukamal, K. J., S. E. Chiuve, E. B. Rimm, K. J. Mukamal, S. E. Chiuve, and E. B. Rimm. 2006. Alcohol consumption and risk for coronary heart disease in men with healthy lifestyles. Archives of Internal Medicine 166(19):2145-2150.

Musunuru K, Kral BG, Blumenthal RS, et al. (2008). The use of high-sensitivity assays for Creactive protein in clinical practice. Nat Clin Pract Cardiovasc Med , 5, 621-625.

National Cholesterol Education Program (NCEP): Expert Panel on Detection, Evaluation, and Treatment of High Blood Cholesterol in Adults (Adult Treatment Panel III final report, 2002. Circulation 106:3143.

Nestel PJ, Yamashita T, Sasahara T, Pomeroy S, Dart A, Komesaroff P, et al, 1997. Soy isoflavones improve systemic arterial compliance but not plasma lipids in menopausal and perimenopausal women. Arterioscler Thromb Vasc Biol; 17 (12):3392-8.

Oken, E., E. B. Levitan, and M. W. Gillman. 2008. Maternal smoking during pregnancy and child overweight: Systematic review and meta-analysis. International Journal of Obesity 32(2):201-210. 
Osmond, C., and D. J. P. Barker. 2000. Fetal, infant, and childhood growth are predictors of coronary heart disease, diabetes, and hypertension in adult men and women. Environmental Health Perspectives 108(Suppl 3):545-553.

Pietinen P, Rimm EB, Korhonen P et al. ,1996. Intake of dietary fibre and risk of coronary heart disease in a cohort of Finnish men. The Alpha-Tocopherol, Beta carotene Cancer Prevention Study. Circulation, 94, 2720-7.

Pilote, L., K. Dasgupta, V. Guru, K. H. Humphries, J. McGrath, C. Norris, D. Rabi, J. Tremblay, A. Alamian, T. Barnett, J. Cox, W. A. Ghali, S. Grace, P. Hamet, T. Ho, S. Kirkland, M. Lambert, D. Libersan, J. O'Loughlin, G. Paradis, M. Petrovich, and V. Tagalakis. 2007. A comprehensive view of sex-specific issues related to cardiovascular disease. Canadian Medical Association Journal 176(6):S1-S44: Erratum 176(9):1310.

Rawson ES et al, 2001. Body mass index, but not physical activity, is associated with Creactive protein, Med Sci Sports Exerc 35 :1160.=

Regitz-Zagrosek, V. 2006. Therapeutic implications of the gender-specific aspects of cardiovascular disease. Nature Reviews Drug Discovery 5(5):425-438.

Rehm, J., C. Mathers, S. Popova, M. Thavorncharoensap, Y. Teerawattananon, and J. Patra.2009. Global burden of disease and injury and economic cost attributable to alcohol use and alcohol-use disorders. Lancet 373(9682):2223-2233.

Richardson DP , 2000. The grain, the wholegrain and nothing but the grain: the science behind the wholegrain and the reduced risk of heart disease and cancer. Nutrition Bulletin, 25, 353-60.

Ridker PM, Buring JE, Shih J 1998. Prospective study of C-reactive protein and the risk of future cardiovascular events among apparently healthy women. Circulation, 97, 425-8

Ridker PM, Hennekens CH, Buring JE, Rifai N ,2000. Creactive protein and other markers of inflammation in the prediction of cardiovascular disease in women. $N$ Engl J Med, 342, 836-43.

Ridker PM, Danielson E, Fonseca FA, et al ,2008. Rosuvastatin to prevent vascular events in men and women with elevated C-reactive protein. N Engl J Med;359:2195-2207.

Ridker PM, Danielson E, Fonseca FA, et al ,2009.. Reduction in C-reactive protein and LDL cholesterol and cardiovascular event rates after initiation of rosuvastatin: a prospective study of the JUPITER trial. Lancet ;373:1175-1182.

Ross R ,1999. Mechanisms of disease - atherosclerosis - an inflammatory disease. New England Journal of Medicine, 340, 115-26.

Rudd JHF et al: Imaging of atherosclerosis-can we predict Plaque rupture?Trends Cardiovasc Med 15:17,2005.

Sassi, F., M. Cecchini, J. Lauer, and D. Chisholm. 2009. Improving lifestyles, tackling obesity: The health and economic impact of prevention strategies. Paris: OECD.

Scanu AM and Edelstein C, 2008. HDL: bridging past and present with a look at the future. The FASEB Journal 22, 4044-54.

Schulze, M. B., F. B. Hu. 2005. Primary prevention of diabetes: What can be done and how much can be prevented? Annual Review of Public Health 26:445-467.

Shafey, O., M. Eriksen, H. Ross, and J. Mackay. 2009. The tobacco atlas. 3rd ed. Atlanta: American Cancer Society. 
Sharifi N, Mahdavi R, Ebrahimi-Mameghani M. Association between physical activity and lipid profile in a sample of women with central obesity. First National Congress of Metabolic Syndrome, Tabriz, Iran. 13-14 June, 2008.

Singhal, A., M. Fewtrell, T. J. Cole, and A. Lucas. 2003. Low nutrient intake and early growth for later insulin resistance in adolescents born preterm. Lancet 361(9363):1089-1097.

Singhal, A., T. J. Cole, M. Fewtrell, J. Deanfield, A. Lucas, A. Singhal, T. J. Cole, M. Fewtrell, J. Deanfield, and A. Lucas. 2004. Is slower early growth beneficial for long-term cardiovascularhealth? Circulation 109(9):1108-1113.

Skalen K, Gustafsson M, Knutsen Rydberg E et al , 2002. Subendothelial retention of atherogenic lipoproteins in early atherosclerosis. Nature, 417, 750-4. susceptibility among six low density lipoprotein subfractions of differing density and particle size. Atherosclerosis, 93, 189-99.

Trichopoulou et al, 2003. Adherence to a Mediterranean diet and survival in a Greek population, $N$ Engl J Med 348:2599.

Truswell AS ,2002. Cereal grains and coronary heart disease. European Journal of Clinical Nutrition, 56, 1-14.

Turnbull, F. M., C. Abraira, R. J. Anderson, R. P. Byington, J. P. Chalmers, W. C. Duckworth, G. W. Evans, H. C. Gerstein, R. R. Holman, T. E. Moritz, B. C. Neal, T. Ninomiya, A. A. Patel, S. K. Paul, F. Travert, and M. Woodward. 2009. Intensive glucose control and macrovascular outcomes in type 2 diabetes. Diabetologia. DOI 10.1007/s0012500009-01470-00120.

US Department of Health and Human Services, 1996. Physical Activity and Health: A Report of the Surgeon General. US Department of Health and Human Services, Centers for Disease Control and Prevention, Atlanta.

Victora, C. G., L. Adair, C. Fall, P. C. Hallal, R. Martorell, L. Richter, and H. S. Sachdev. 2008. Maternal and child undernutrition: Consequences for adult health and human capital. Lancet 371(9609):340-357.

Walker, S., and S. George. 2007. Young@heart. USA: Fox Searchlight Pictures.

Wannamethee SG, Shaper AG, 2002. Physical activity and cardiovascular disease. Seminars in Vascular Medicine, 2, 257-65.

Whitaker, R. C. 2004. Predicting preschooler obesity at birth: The role of maternal obesity in early pregnancy. Pediatrics 114(1):e29-e36.

WHO.2003. The world health report: 2003: Shaping the future. Geneva: World Health Organization.

WHO.2005.Preventing chronic diseases: A vital investment. http://www.who.int/chp/chronic_ disease_report/full_report.pdf (accessed April 23, 2009).

WHO. 2008a. The global burden of disease: 2004 update. Geneva: World Health Organization.

WHO. 2008b. WHO report on the global tobacco epidemic, 2008 : The MPOWER package. Geneva: World Health Organization.

WHO. 2009a. World health statistics 09 . Geneva: World Health Organization.

WHO. 2009b. Global health risks: Mortality and burden of disease attributable to selected major risks. Geneva: World Health Organization.

WHO. 2009 c. Aging and life course. Geneva: World Health Oranization.

WHOSIS (World Health Organization Statistical Information System). 2009. World Health Organization. 
Wijendran V and Hayes KC, 2004: Dietary n-6 and n-3 fatty acid balance and cardiovascular health. Annu Rev Nutr 24:597.

Willett WC, 1998. Is dietary fat a major determinant of body fat? American Journal of Clinical Nutrition, 67, 556S-62S.

Williams CL, Hayman LL, Daniels SR et al., 2002. Cardiovascular health in childhood: a statement for health professionals from the Committee on Atherosclerosis, Hypertension, and Obesity in the Young (AHOY) of the Council on Cardiovascular Disease in the Young, American Heart Association. Circulation, 106, 143-60.

Ziegelstein, R. C., J. A. Fauerbach, S. S. Stevens, J. Romanelli, D. P. Richter, and D. E. Bush. 2000. Patients with depression are less likely to follow recommendations to reduce cardiac risk during recovery from a myocardial infarction. Archives of Internal Medicine 160(12):1818-1823. 


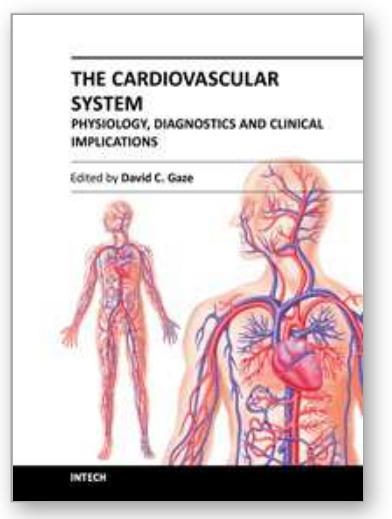

\author{
The Cardiovascular System - Physiology, Diagnostics and Clinical \\ Implications \\ Edited by Dr. David Gaze
}

ISBN 978-953-51-0534-3

Hard cover, 478 pages

Publisher InTech

Published online 25, April, 2012

Published in print edition April, 2012

The cardiovascular system includes the heart located centrally in the thorax and the vessels of the body which carry blood. The cardiovascular (or circulatory) system supplies oxygen from inspired air, via the lungs to the tissues around the body. It is also responsible for the removal of the waste product, carbon dioxide via air expired from the lungs. The cardiovascular system also transports nutrients such as electrolytes, amino acids, enzymes, hormones which are integral to cellular respiration, metabolism and immunity. This book is not meant to be an all encompassing text on cardiovascular physiology and pathology rather a selection of chapters from experts in the field who describe recent advances in basic and clinical sciences. As such, the text is divided into three main sections: Cardiovascular Physiology, Cardiovascular Diagnostics and lastly, Clinical Impact of Cardiovascular Physiology and Pathophysiology.

\title{
How to reference
}

In order to correctly reference this scholarly work, feel free to copy and paste the following:

Reza Amani and Nasrin Sharifi (2012). Cardiovascular Disease Risk Factors, The Cardiovascular System Physiology, Diagnostics and Clinical Implications, Dr. David Gaze (Ed.), ISBN: 978-953-51-0534-3, InTech, Available from: http://www.intechopen.com/books/the-cardiovascular-system-physiology-diagnostics-andclinical-implications/cardiovascular-risk-factors

\section{INTECH}

open science | open minds

\author{
InTech Europe \\ University Campus STeP Ri \\ Slavka Krautzeka 83/A \\ 51000 Rijeka, Croatia \\ Phone: +385 (51) 770447 \\ Fax: +385 (51) 686166 \\ www.intechopen.com
}

\author{
InTech China \\ Unit 405, Office Block, Hotel Equatorial Shanghai \\ No.65, Yan An Road (West), Shanghai, 200040, China \\ 中国上海市延安西路65号上海国际贵都大饭店办公楼405单元 \\ Phone: +86-21-62489820 \\ Fax: +86-21-62489821
}


(C) 2012 The Author(s). Licensee IntechOpen. This is an open access article distributed under the terms of the Creative Commons Attribution 3.0 License, which permits unrestricted use, distribution, and reproduction in any medium, provided the original work is properly cited. 